conjunction with an adjacent committee room and cloakroom, as a self-contained suite available for professional bodies and societies.

This Department is responsible for the education and training of pharmacists who may enter hospitals, industry or retail work. The College is affiliated, in respect of this work, to the University of Wales, so that students can take either the B.Pharm.(Wales) or the pharmaceutical chemist qualifying course. The Department has been designed for an annual intake of 64 students for a three-year course, but this could be increased to 96 without much difficulty.

The Department is an active research centre and is recognized by the University as a place for research for M.Pharm., while application has been made for recognition for $\mathrm{Ph} . \mathrm{D}$. There have now been seven M.Pharm. awards to members of the College.

Research at present in progress in the Department includes: physico-chemical studies on phosphatides; kinetics of the bromination of phenolic aldehydes; synthetic studies on rotenoids; synthesis of $2: 2$ dimethylchromenes which may have physiological activity; synthesis of apomorphine derivatives; synthesis of sulphones as antibacterials; properties of liquorice and its constituents, with particular reference to its value as a pharmaceutical excipient; control and prediction of particle size in ball milling; conductance of emulsions; effect of moisture on porcelain dental fillings; chromatographic techniques applied to crude vegetable drugs; pharmacology and biochemistry of substituted glutarimides; cotton dust and other vegetable dusts in relation to byssinosis; macrocyclic compounds related to steroid hormones; action of bases on chloroform; transformation of glycyrrhetic acid; changes in drug sensitivity in states of avitaminosis.

The Navigation Department occupies the bulk of the two upper floors above the Students' Union. Apart from a small amount of part-time work for vachtsmen, its function is the preparation of serving merchant navy officers for Ministry of Transport Certificates of Competency. It is exceptionally well equipped, as befits the only Navigation Department in a College of Advanced Technology. One special feature is an instrument room, which houses all the aids, electronic or otherwise, which an officer might find on the bridge of a modern merchant ship. A radar simulator (costing $£ 12,000$ ) is now being installed, and this will supplement the training given in the College Radar School at Cardiff docks. Another interesting feature is an extremely compact demonstration set-up, where twenty students can sit around the working bench with not one of them more than $6 \mathrm{ft}$. from the demonstration.

The communal facilities in this new building include a refectory, kitchen, etc. Above this, and extending through the two upper floors, is the Great Hall. Measuring $80 \mathrm{ft} . \times 60 \mathrm{ft}$., this hall, with its gallery, can provide seating for nearly 800 . It has a large stage, fully equipped, with ancillary stores and storage space, and two dressing-rooms. A large window at the back of the gallery enables the classroom behind it to be used as a control room for radio and television programmes. Access to the building is arranged in such a way that the great hall can be used without interfering with the rest of the building. The meetings of the British Association for the Advancement of Science, 1960, saw the first use of the Hall, and a number of exhibitions have already been held in it, including one staged by the United Kingdom Atomic Energy Authority.

Finally, reference must be made to the Students' Union. This is a self-contained suite of rooms of some $5,000 \mathrm{sq}$. ft. and the accommodation includes two lounges, two recreation rooms, a council room, chapel, a music room, a photographic room, together with various offices for the conduct of Union business. Although the Union has always been a very live body, the improvement in facilities has already resulted in a marked development of student activities.

\title{
GAS-PHASE REACTIONS OF THE HALOGENS AND THEIR COMPOUNDS
}

\begin{abstract}
A $\mathrm{N}$ informal discussion on "Mechanisms of the A Gas-Phase Reactions of the Halogens and their Compounds" was held on March 28 at University College, Cardiff, under the auspices of the Faraday Society. About seventy members and guests were present. The chairman of the first session, Prof. A. G. Evans (Cardiff), welcomed the visitors to Cardiff and introduced the foreign guests. Dr. P. G. Ashmore (Cambridge) then reported further investigations in his detailed study of the pyrolysis of nitrosyl chloride. He showed that the addition of nitrogen dioxide to nitrosyl chloride leads to a fast but rapidly inhibited decomposition. The catalysis was explained by postulating the intermediate formation of nitryl chloride, that is :
\end{abstract}

$$
\begin{gathered}
\mathrm{NOCl}+\mathrm{NO}_{2} \stackrel{12}{\rightarrow} \mathrm{NO}_{2} \mathrm{Cl}+\mathrm{NO} \\
\mathrm{NO}_{2} \mathrm{Cl}+\mathrm{M} \stackrel{14}{\rightarrow} \mathrm{NO}_{2}+\mathrm{Cl}+\mathrm{M} \\
\mathrm{NO}_{2} \mathrm{Cl}+\mathrm{NOCl} \stackrel{15}{\rightarrow} \mathrm{NO}_{2}+\mathrm{NO}+\mathrm{Cl}_{2}
\end{gathered}
$$

The auto-inhibition was explained by reaction of the product nitric oxide with nitryl chloride :

$$
\mathrm{NO}+\mathrm{NO}_{2} \mathrm{Cl} \stackrel{13}{\rightarrow} \mathrm{NO}_{2}+\mathrm{NOCl}
$$

Estimates were given for $k_{14}$ with $M=\mathrm{NO}_{2}$ and $\mathrm{N}_{2}$ and new values had been obtained for $k_{3}$ in the reaction :

$$
\mathrm{NOCl}+M \stackrel{3}{\rightarrow} \mathrm{NO}+\mathrm{Cl}+M
$$

with $M=\mathrm{NOCl}, \mathrm{NO}, \mathrm{N}_{2}$ and $\mathrm{H}_{2}$. One surprising feature of these last results was the very small differences found for the activation energies and preexponential factors when $M$ was varied.

The second paper by Prof. R. G. W. Norrish (Cambridge) gave an account of the flash photolysis of nitrosyl chloride in the presence of a large excess of inert gas to ensure isothermal conditions. Many absorption bands were produced in the region 2100-4000 \&. The conditions of the experiments were such that the light causing photolysis was mainly in the region below $2700 \AA$. Since the $\mathrm{N}-\mathrm{Cl}$ bond 
in NOCl has a dissociation energy of approximately $38 \mathrm{kcal}$, this corresponds to an excess energy of 70-110 kcal. (at the limit of transmission of quartz). The absorption bands in the spectrum that follows the flash have been assigned to transitions from the ground-state of NO $\left(X^{2} \pi\right)$ to excited states $A^{2} \varepsilon$, $B^{2} \varepsilon, C^{2} \pi$ and $D^{2} \varepsilon$, and it was demonstrated that all vibrational levels of the ground-state up to $v^{\prime \prime}=10$ were populated.

Norrish was able to show that at least $50 \mathrm{kcal}$. of the excess energy of the flash appears as vibrational energy in the nitric oxide molecule, and suggested that this occurs in the primary process, namely:

$$
\mathrm{NOCl}+h_{\nu} \rightarrow \mathrm{NO}^{*}+\mathrm{Cl}
$$

Various other possibilities were discounted on energetic or theoretical grounds.

Finally, he suggested that such a process may have a fairly wide generality, and could explain the production of many of the highly vibrationally excited molecules produced in flash photolysis.

Dr. J. H. Thomas (Cardiff) then discussed the gasphase reactions of methyl chloride, methylene chloride and chloroform with nitrogen dioxide. He showed that the reactions were autocatalytic in nature, and led to complex oxidation products. Two of the products, hydrogen chloride and nitrosyl chloride, had marked catalytic effects when added to the initial reactants, as did the addition of chlorine. $\mathrm{He}$ suggested that the autocatalysis resulted from the production of chlorine atoms by reactions such as :

and

$$
\mathrm{HCl}+\mathrm{NO}_{2} \rightarrow \mathrm{Cl}+\mathrm{HNO}_{2}
$$

$$
\mathrm{NOCl} \rightarrow \mathrm{NO}+\mathrm{Cl}
$$

followed by hydrogen abstraction by the chlorine atoms, for example:

$$
\mathrm{CH}_{3} \mathrm{Cl}+\mathrm{Cl} \rightarrow \mathrm{CH}_{2} \mathrm{Cl}+\mathrm{HCl}
$$

The final products were explained by a mechanism involving further reactions of the radicals produced in (3). The reactions of the three chloromethanes were compared, and it was explained that carbon tetra. chloride was unreactive until much higher tempera. tures were reached.

In the second session, with Prof. R. G. W. Norrish in the chair, two papers on aspects of the photochlorination of chlorinated ethylenes were presented by Prof. F. S. Dainton (Leeds) and Prof. P. Goldfinger (Brussels). These reactions all involve chains initiated by chlorine atoms via :

$$
A+\mathrm{Cl} \underset{2}{\stackrel{1}{\rightleftharpoons}} A \mathrm{Cl}
$$

where $A$ is an olefine. The radical $A C l$ finishes in the main as $A \mathrm{Cl}_{2}$ and various chain-termination steps may occur. Both groups of workers used experiments with intermittent light to find the Arrhenius parameters for the various chain steps.

Dainton has studied the olefines $\mathrm{C}_{2} \mathrm{H}_{n} \mathrm{Cl}_{4-n}, n=0-4$, with the exception of vinylidene chloride. Reaction (1) is very exothermic for these olefines, hence the $A C l$ radical should have considerable energy and may be regarded as an excited molecule $A \mathrm{Cl}^{*}$. The Arrhenius paremeters for reaction (2) should then be quite different from those for the decomposition of a normal $A C l$ radical. This was found to be so for $A=$ vinyl chloride, where $E_{2}=0.7 \mathrm{kcal}$. mole ${ }^{-1}$ compared with $E_{2}=22 \cdot 0 \mathrm{kcal}$. mole ${ }^{-1}$ from pyrolysis studies.
Goldfinger has studied trichloroethylene to find out if reaction (1) above gives the symmetric $\left(\mathrm{CCl}_{2} . \mathrm{CCl}_{2} \mathrm{H}\right)$ or asymmetric $\left(\mathrm{CCl}_{3}\right.$. $\dot{\mathrm{CHCl}}$ ) radical. The method used involved the photochlorination of trichloroethylene in the presence of either sym. or asym. tetrachloroethane (since hydrogen abstraction by chlorine atoms from the last two substances will give the sym. and asym. radicals referred to above). An analysis of the kinetics of the reactions of these mixtures showed that reaction (1) gives the sym. radical, that is :

$$
\mathrm{CHCl}=\mathrm{CCl}_{2}+\mathrm{Cl} \rightarrow \mathrm{CHCl}_{2}-\mathrm{CCl}_{2}
$$

The activation energy for the reverse of this reaction was found to be $19 \mathrm{kcal}$. mole-1, which is much larger than the value of $6.6 \mathrm{kcal}$. mole-1 found by Dainton for the same reaction. Goldfinger was unable to find evidence of the formation of excited $A C l$ radicals.

After lunch, Prof. E. C. Kooyman (Leyden) was chairman and the first speaker was Dr. E. Whittle (Cardiff), who described the photosensitized brominations of methanol, ethanol, formaldehyde and acetaldehyde. The main purpose of these investigations was to obtain information about the strengths of certain of the bonds in the molecules. The products of the reaction were identified and explained in terms of chain reactions involving bromine atoms. Dr. Whittle discussed in detail the photobromination of methanol and its kinetics under varying conditions, which resulted in different chain termination pro-

$$
\text { cesses. The reaction } \mathrm{Br}+\mathrm{CH}_{3} \mathrm{OH} \underset{2}{\stackrel{1}{\rightleftharpoons}} \mathrm{CH}_{2} \mathrm{OH}+\mathrm{HBr}
$$

was found to have an activation energy $E_{1}=$ $6 \mathrm{kcal}$. mole ${ }^{-1}$. This gives $\Delta \mathrm{H}_{1} \leqslant 4 \mathrm{kcal}$. mole ${ }^{-1}$ and hence $\mathrm{D}\left(\mathrm{H}-\mathrm{CH}_{2} \mathrm{OH}\right) \leqslant 92$ kcal. mole ${ }^{-1}$. The $\mathrm{CH}$ bond in methanol is thus considerably weaker than in methane, for which $\mathrm{D}\left(\mathrm{H}-\mathrm{CH}_{3}\right)=102 \mathrm{kcal}$. mole-1.

Dr. J. M. Tedder (Sheffield) then discussed the fluorination, chlorination and bromination of the butanes and normal and secondary butyl halides. For unsubstituted butanes the activation energy for abstraction of hydrogen atoms by different halogen atoms are of the order : fluorination $100 \mathrm{cal}$. mole-1, chlorination 1,000 cal. mole -1 bromination 10,000 cal. mole ${ }^{-1}$. In all cases the activation energies decrease for different hydrogen atoms in the order tertiary $<$ secondary < primary.

The introduction of substituent halogen atoms into butane has a considerable effect on the rates of halogenation of sites adjacent to the substituent. The previously accepted assertion that a substituent halogen atom directs attack by chlorine atoms away from itself was shown to be incorrect, for example, in the chlorination of 2-chlorobutane the dichlorobutane formed in the largest amount was 2.2-dichlorobutane. For brominations similar effects were found, but in the fluorination of 2 halobutanes only slight attack occurs at the 2- position. The experimental results were interpreted in terms of the Evans and Polanyi picture of the transition state.

The final session with Prof. F. S. Dainton in the chair was opened by Prof. Kooyman, who described the results of a study of the products of the chlorination and bromination of aromatic materials in the gas phase. Chlorinations were carried out at temperatures between $300^{\circ}-450^{\circ}$ C. and brominations between $400^{\circ}-500^{\circ} \mathrm{C}$. Typical reactions were between bromine or chlorine and diphenyl ether, fluorobenzene, chlorobenzene and benzonitrile. The striking feature 
of all these reactions is that substitution occurs with major products being the meta-isomers. This is in complete contradiction in all cases to liquid-phase halogenations where ortho/para substitution predominates.

Kooyman said that a radical mechanism ulone could not readily explain the specificity of the results obtained and put forward the novel suggestion that the reactions occurred through an ionic intermediate, that is :

$$
\begin{aligned}
X_{2} & \rightarrow 2 X \\
X+\mathrm{ArH} & \rightarrow[\mathrm{ArH}+]\left[X^{-}\right]
\end{aligned}
$$

A proton is then lost from the position with highest positive charge, that is, the meta position :

$$
\begin{gathered}
{\left[\mathrm{ArH}^{+}\right]\left[X^{-}\right] \rightarrow \mathrm{Ar}+\mathrm{H} X} \\
\mathrm{Ar}+X_{2} \rightarrow \operatorname{Ar} X+X
\end{gathered}
$$

This mechanism provoked a lively discussion, and the outcome of Prof. Kooyman's present work on the kinetics of these reactions is awaited with interest.
Finally, Dr. B. A. Thrush (Cambridge) described spectroscopic studies of bromine atom recombination. The studies employed the technique of flash photolysis to study the recombination of bromine atoms in ixcess argon to determine whether the bromine molecules formed in the recombination are produced in an electronically excited state or with excess vibrational energy. No evidence for the former was found but absorption spectra obtained during the recombination showed an appreciable increase in the population of the lower excited vibrational levels of the ground-state, notably $v^{\prime \prime}=1,2,3,4$ and 5 .

The distribution of this energy corresponded to temperatures much higher than those to be expected from the amount of energy absorbed from the flash.

The papers presented stimulated a lively discussion throughout and thus ensured the success of the meeting.

\section{J. H. Thомas}

E. WhitrLe

\section{AUTHOR AND PUBLISHER}

$\mathrm{P}^{\mathrm{H}}$ OBLEMS arising in connexion with the publication of scientific books were discussed at a recent meeting of the Scientific Publications Council held at the Ciba Foundation, London. Prof. G. W. Harris was in the chair.

Mr. David Dickens (Pitman Medical Publishing Co.) said that the publication of scientific books is not a lucrative business. Seientifie books are generally written for the specialist, and consequently the market for them is small. A publisher of scientific text-books must maintain a staff of highly qualified editors and sub-editors, generally with science degrees, who work together with the authors to get the manuscripts into shape for publication. This is often a long process involving heavy investment: one book alone might cost $\mathfrak{f 4 , 5 0 0}$ to produce and may take many years to bring back the outlay. The publisher contributes, as indicated by his 'imprint', prestige, knowledge of the field and 'know-how'. $\mathrm{He}$ has the same interest as the author in getting a book published as quickly as he can.

\section{Ownership of Copyright}

$\mathrm{Mr}_{\mathrm{r}}$. Dickens stated that the copyright is the author's as soon as he puts pen to paper. The publisher is generally better able to deal with selling the rights than the author, and he should do this in the author's name. Difficulties may arise if a book is written by joint authors who later decide to part. Mr. D. M. Neale (Oxford University Press) believed that it is often more convenient for the publisher to hold the copyright in order to protect the author's interests, although this is not necessarily a good general rule. His firm has been taking legal action to stop a book being pirated in Hong Kong: it could not have done this if the copyright were in the author's name, since the author was in Europe doing research. The cost of fighting an action of this kind is enormous and is all borne by the firm. When an institute publishes a series of volumes, the copyright is sometimes held by the institute: otherwise the Oxford University Press prefers to keep the copyright and return to the author whatever they may get from sale of the rights. Difficulties can arise if a publisher holding the copyright is taken over by another firm: the author has generally no defence against that. Miss M. E. Barber (Society of Authors) said that some publishers never take the copyright, but others do claim it, often in the first clause of the contract. The copyright includes translation, broadcasting, television, film, drama, digests and paperback editions. The Society of Authors takes the view that the publisher does not need the copyright: he should negotiate the rights as the author's agent. Scientists often regard writing as a side-line, and they do not take the trouble they should over contracts: publishers therefore treat scientists in a way in which they would not treat other authors. Only if piracy were rife enough to be an overriding consideration would it be justified for the publisher to hold the copyright.

Mr. A. L. Bacharach (Nutrition Society) said that the author of a paper in a scientific journal is in a different position from the same author when writing a text-book. The copyright of a scientific paper is owned by the author, unless he has specifically assigned it to a body, such as a learned society: but recently it has been suggested that the copyright of a paper belongs to the employer of the author. Dr. E. A. Moelwyn-Hughes (Cambridge) said that some countries still take no notice of copyright. When in the U.S.S.R. he had discovered by chance that 20,000 copies of a book by him had been distributed there, but he had received no royalties from the Russians. He had heard that there was also a Japanese edition, from which he also had no royalties. It is generally understood that an author can quote material from another publication so long as he gives the source and reference, but some publishers object to this. What is the legal position? Miss Barber replied that quoting from another publication is often done by scientists, but it is an infringement of copyright to quote "a substantial part" of a copyright work without permission. Even summarizing a publication of another author or publishing an abstract is an infringement of copyright if done without permission. 